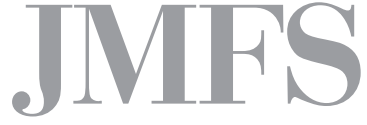

Journal of Management and Financial Sciences
Volume XI

Issue 31 (March 2018)

pp. $49-57$

Warsaw School of Economics

Collegium of Management and Finance

Joanna Radomska

Wroclaw University of Economics

Strategic Management Department

\title{
Company Creativity Reflected in the Visionary Strategic Approach: Implications for Strategy Implementation ${ }^{1}$
}

\begin{abstract}
This article investigates an organisational creativity reflected by a strategic approach. An approach called visionary, in which environment changes can be anticipated and created, was analysed. As creativity seems an inherent aspect of an organisation's activity - at the organisational and the conceptual levels, it could be reflected in an innovative development concept. Hence, the purpose of this article is to indicate implications related to strategy implementation by companies with a visionary strategic approach. As shown by the research results, the degree of strategic goal achievement in that group of companies should be recognised as high. It is negatively correlated with different areas of operational risk (intra-organizational) being present in the strategy implementation process. The highest level of correlation was indicated for the area related to employees, who are the basis of creative potential of every organisation, especially those with a strategic approach.
\end{abstract}

Keywords: visionary strategic approach, strategy execution, creativity JEL Classification Codes: L25, L21

\footnotetext{
1 Project No. 2014/13/D/HS4/01425 was financed by the National Science Centre.
} 


\section{Introduction}

Many studies indicate the necessity of an organisation to adapt to some changing conditions, especially to a higher versatility of the more dynamic competitive environment. The character of the industry and the necessity to maintain the existing competitive advantage often require much creativity reflected in the strategic approach. It means taking actions aimed at integrating, adjusting, and developing capabilities and resources possessed [Reeves, 2016, p. 24]. They are components of organisational creativity that can be identified at the operational level as well as the conceptual level, being a certain distinctive feature of an organisation [Bujor, Avasilcai, 2016, p. 23] not only perceived from the perspective of individual skills [Montuori, Purser, 1995, pp. 69-112]. In the latter case, it is an element of the cognitive process that differs, depending on competences and skills, as a personality feature [Friedman, Forster, 2001, pp. 1001-1013]. And as for strategic management, the visionary strategic approach could be analysed as a manifesto of creativity as an organisation's feature. That is mainly because it requires anticipating the environment changes and seeking new ways of shaping it [Montag-Smit, Maertz, 2017, pp. 1-10]. Hence, the purpose of this study is to investigate the implications related to strategy implementation for companies with the visionary strategic approach. To achieve that goal the paper was structured as follows. Based on the literature review presented, the research hypothesis was formulated and presented in the research methodology section. The research results were further analysed and discussed. The implications were formulated in the summary.

\section{Literature review}

There are many research concepts in strategic management literature, for which the strategy creation and implementation process is creative by nature [Smircich, Stubbart, 1985, pp. 724-36]. On the one hand, this creativity concerns a creation of new and useful concepts [Thomson, 2003, p. 96], while on the other - the visionary approach to strategic management process [Dewett, 2004, p. 168]. For that reason, the creativity of a company can be interpreted bidirectionally - as a capability of creating innovative and original ideas and designing activities for their implementation [Lavoie, 2015, p. 214]. The common result of both concepts is gaining competitive advantage. Therefore, organisational creativity means a certain concept of designing the organisational development based on implementing an original and visionary strategy [Mitchcell, Walinga, 2017, p. 1875].

Similarly, the visionary approach is defined as a philosophy of planning strategic activities and implementing those plans, while generating capabilities to be dynamic and creative, yet task-oriented [Rapmersad, 2001, pp. 211-214]. According to Bonn [2005, p. 338], there is a strong relation between the visionary approach, creativity and strategic thinking concepts. 
As strategy means implementation of innovative, often visionary solutions to gain competitive advantage, strategic thinking is based on the necessity to search for new approaches and anticipate more effective methods of action, hence creativity.

The assumptions of a more creative definition of strategies implemented is the basis of the concept of Reeves, Haanaes and Sihna, according to which organisations can be classified based on their strategic approach. The variables are the nature of the environment where the company operates and the possibility of shaping it through planned actions and achieving the main goals. The underlying assumptions are that a business environment differs in three specified dimensions: unpredictability (an ability to anticipate), malleability (an ability to affect), and an ability to survive. Their combination (matrix) allows distinguishing five types of environment, each requiring different creativity manifested by a versatile approach to formulating and implementing strategies.

This study describes the visionary approach for which an organisation can anticipate changes and affect them, meaning an ability to create new markets and consumers' needs (called "being first"). It allows implementation of innovative strategies, requiring the courage to follow the chosen path consistently and to engage the necessary resources [Reeves et. al., 2015, p. 7].

Due to the complexity and creativity level, the strategic approach can be treated as one of the factors affecting the way and the possibilities of implementing the strategy developed. For that reason, it is worth checking if the creativity reflected in an individual strategic approach affects the operational (intra-organizational) risk related to this process. It is worth mentioning that the risk is one of the criteria considered while choosing the strategic approach. The possibilities of determining risk, its anticipation or restriction resulting from the approach adopted are considered. Also, different intra-organizational risk factors can be determined for every strategic approach, which results from a different approach to strategic analysis, different resource potential, or the way to design and measure the implementation process. Those aspects result from a versatile level of creativity in organizations.

\section{Research methods}

The questionnaire proposed by Reeves, Haanaes and Sinha [2015, pp. 215-217] was used to investigate the type of strategic approach. Within this concept, the main research included determining the ability to anticipate changes in the environment (determining the sector predictability - the advance and accuracy of anticipating the demand, company results, competence dynamics, and market expectations) and the capability of affecting them (determining the malleability, hence the level of impact on the above-mentioned factors). The companies could be classified as one of five strategic approach types. The research sample contained 150 entities quoted on the Warsaw Stock Exchange and on the alternative New Connect market, different in the size and branch in which they run their activity. The research sample was chosen, because the presence on the stock exchange requires determining and precisely specifying a strategy 
and strategic goals and reporting the progress. A visionary strategic approach was recognised in 55 entities (36.7\%). Further research aimed at recognising the strategy implementation (its effectiveness measured by the degree of achieving strategic goals) and to explore the level of operational risk included in this process. Based on the EFQM concept [Fundamental Concepts of Excelence, 2013], 6 areas of operational (intra-organizational) risk were determined - leadership, strategy, employees, resources, processes, and measures. The study was conducted by a research agency using a direct questionnaire interview - the survey was carried out with the use of PAPI and the 5-point Likert scale was used. The respondents were CEOs. The risk level was calculated as the probability of a given factor and the assessment of its impact (coded to scale 1-5 and multiplied). The correlations between the variables were determined using the Pearson correlation. For independent samples, the Kruskal-Wallis analysis of variance was used. The following research hypothesis was formulated:

$H$ : In the group of companies with a visionary strategic approach, there is a negative relationship between the degree of achieving the strategic goals and the level of operational risk associated with strategy implementation.

\section{Sample characteristics}

Before the research results are discussed, it is worth presenting the characteristics of the sample. Among companies with a visionary strategic approach, small entities (49\%) prevail, and the percentage of large companies (employing more than 250 people) is the lowest (22\%). This classification differs from the one indicated for all the respondents, where three categories of entities are distinguished, with a non-significant prevalence of small organisations. Detailed results are presented in Graph 1.

\section{Graph 1. Size of companies with a visionary strategic approach in relation to the entire researched sample}

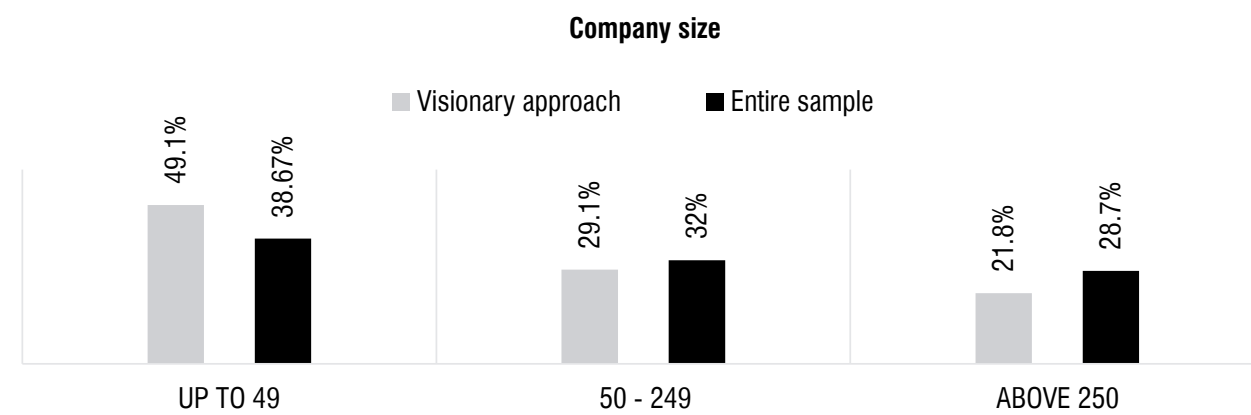

Source: the author's own study based on the research results.

The results are similar to the results of other authors [Roitzsh et. al., 2012, pp. 1-2] indicating larger creativity, flexibility, and the innovative approach of small companies with resources 
allowing faster overcoming the development barriers created by the environment and taking advantage of opportunities recognized [Dean et. al., 1998, pp. 709-728].

In the aspect of the market share, the companies with a visionary strategic approach have values similar to the entire researched sample in two groups distinguished (10\% and $30 \%)$. A higher percentage was noted for the share of $50 \%$ (38\% in relation to $25 \%)$. A lower percentage was noted for the last group (70\% of the market share), as shown in Graph 2.

\section{Graph 2. Market share of companies with a visionary strategic approach in relation to the entire researched sample}

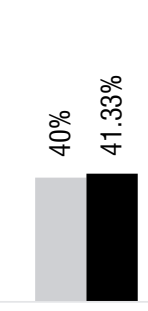

UP T0 10\%

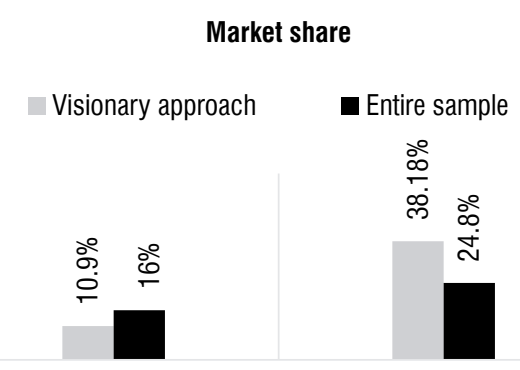

APPROX. $30 \%$

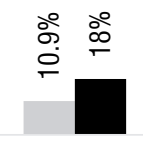

APPROX. $70 \%$

Source: the author's own study based on the research results.

The analysis of the market share shows that the companies with a visionary strategic approach can be divided into two groups: entities with a small share and significant leaders (the share of 50\%). It seems to be related to the industry where the company operates and its characteristics. The branch diversity is shown in graph 3.

\section{Graph 3. Branch diversity of companies with a visionary strategic approach in relation to the entire researched sample}

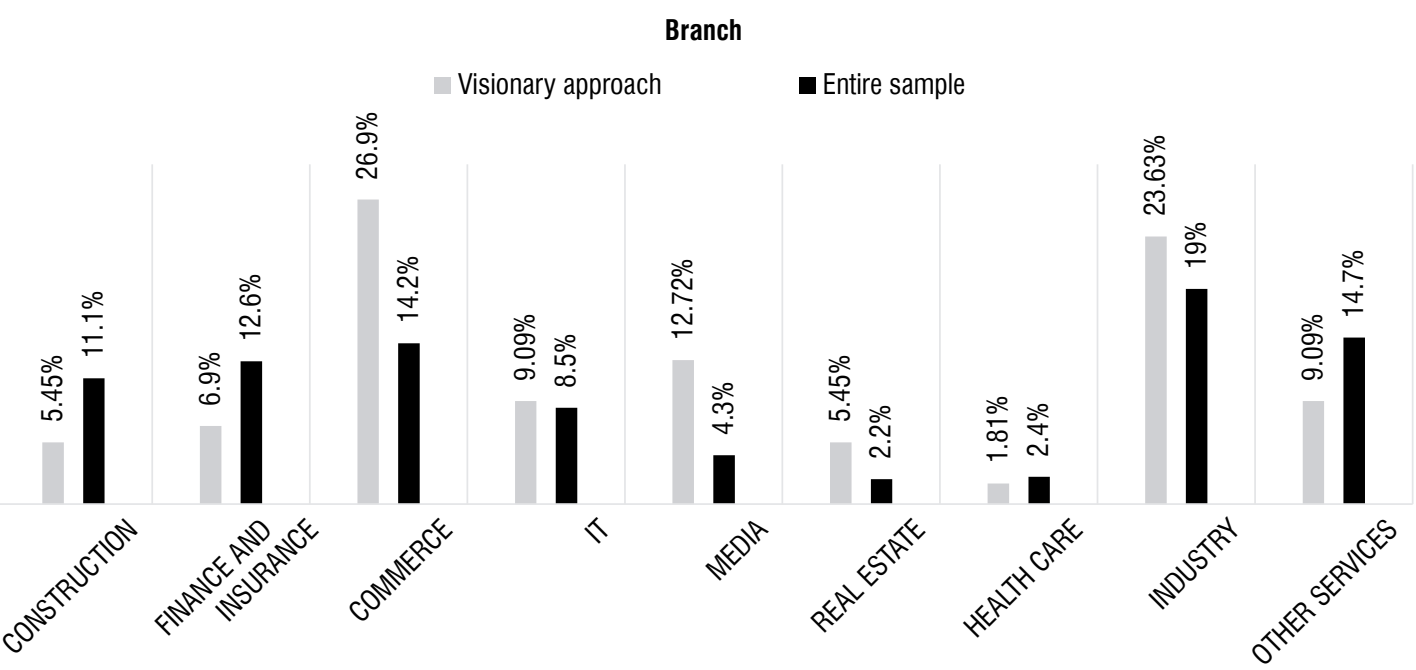

Source: the author's own study based on the research results. 
The results indicate that the companies with a visionary strategic approach have a slightly different branch diversity than the entire researched sample with a significant prevalence of commerce, industry and the media (highly competitive sectors), and a lower percentage of construction or finance.

\section{Research results and discussion}

First, it is worth noticing that statistical tests have not confirmed the relation between the operational risk level in the strategy implementation and the strategic approach (the significance level was higher than 0.05). It means the strategic approach cannot be indicated as the one for which the operational (intra-organizational) risk in strategy implementation is higher than for other approaches. Also, a similar risk level for the distinguished areas was noted, as presented in graph 4 .

\section{Graph 4. Risk level for individual areas in the group of companies with a visionary strategic approach in relation to the entire researched sample}

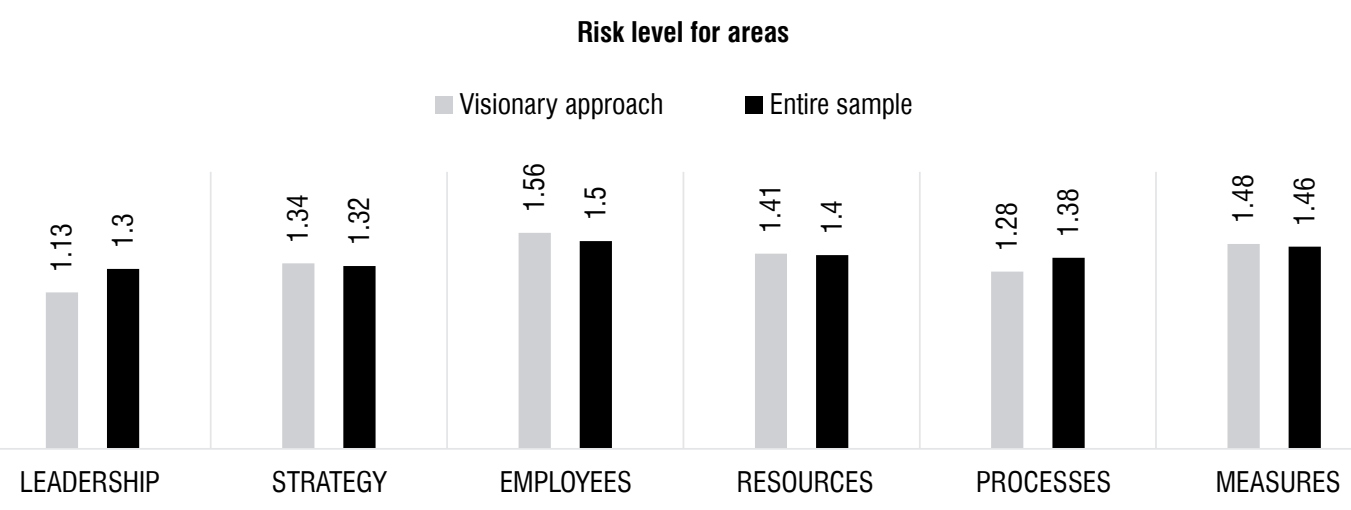

Source: the author's own study based on the research results.

As discussed, the results show that the risk level in the areas is close to the entire researched sample, and the highest level was noted in the area related to employees, which was recognised as the aspect of the highest risk.

Further on, the relation between the degree of achieving strategic goals and the strategic approach was investigated. The Kruskal-Wallis variance analysis for independent samples showed a low level of relevance (0.003), which means the degree of achieving strategic goals and the strategic approach implemented are related. The visionary strategic approach had the highest percentage of achieved strategic goals. Graph 5 shows the results of the analysis in relation to the entire researched sample.

For the visionary strategic approach, the medium level of goal achievement (between 50\% and $74 \%$ ) prevails, with almost $17 \%$ of indications for their highest level (more than $75 \%$ ). 
There is a small number of answers for the lowest group (up to 25\%). This confirms that in the group of companies with a visionary approach, the level of goal achievement is high. Those results are interesting, as the strategic approach is based on anticipating and affecting changes in the environment, which could be considered as an activity requiring significant organisational creativity. However, the respondents indicated a high satisfaction level in the achievement of the initiatives assumed. Thus, it can be concluded that the visionary strategic approach in the researched group is implemented according to the assumptions.

\section{Graph 5. Level of strategic goal achievement in the group of companies with a visionary strategic approach in relation to the entire researched sample}

\section{Level of strategic goals achievement}

Entire sample

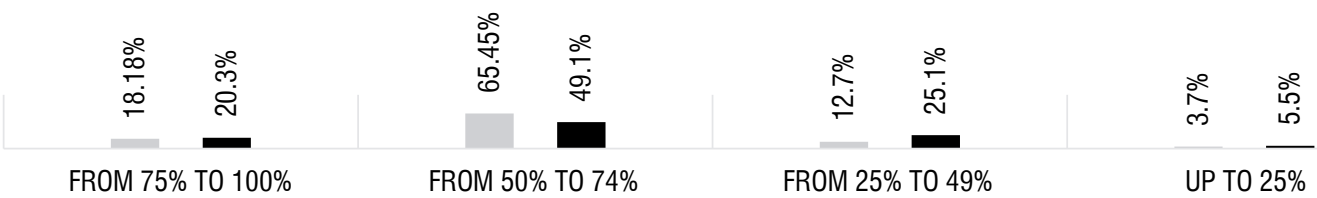

Source: the author's own study based on the research results.

The last aspect analysed was the relation between the level of strategic goals achievement and the operational risk level that can be indicated in the group of companies with a visionary strategic approach, which was the subject of the research hypotheses. The results are shown in Table 1.

Table 1. Correlations between the operational risk level for the areas and the degree of implementation of strategic goals in the group of companies with a visionary strategic approach

\begin{tabular}{|c|l|c|c|c|}
\hline Pos. & \multicolumn{1}{|c|}{ Area } & Pearson correlation & Relevance & N \\
\hline 1. & Leadership & -0.329 & 0.011 & 55 \\
\hline 2. & Strategy & -0.284 & 0.002 & 55 \\
\hline 3. & Employees & -0.392 & 0.001 & 55 \\
\hline 4. & Resources & -0.312 & 0.000 & 55 \\
\hline 5. & Processes & -0.287 & 0.000 & 55 \\
\hline 6. & Measures & -0.246 & 0.000 & 55 \\
\hline
\end{tabular}

Source: the author's own study based on the research results.

The research results indicate statistically relevant negative correlations between the variables. They are weak for three areas $(2,5$, and 6) and moderate for the remaining three areas $(1,3$, and 4$)$. The highest level of relation for the area related to employees (from different levels of organizational structure) can be indicated. It could be recognised as the most crucial of the areas investigated. A negative correlation means that with the growth of the level 
of risk, there is a decrease in the degree of implementation of strategic goals, which seems to be a logical direction of that relation. A similar relation is shown for the results calculated for more operative areas (measures and processes), where the impact of the risk level on the abilities to achieve goals is slightly lower. It can be concluded that more operative areas have a lower impact on the level of strategic goal achievement, as they are more controllable and measurable than the areas where attitude, knowledge, and commitment of the employees and managers matter most. And those are key factors for the approach based on the anticipation and implementation of changes in the environment, where the potential of creativity should be significant. Regardless of the differences in correlation, it can be concluded that the increase of risk level reduces the level of strategic goal achievement (correlation of -0.423), allowing to the acceptance of the research hypotheses.

\section{Summary}

The research concept of this article based on the assumption that organisational creativity can be reflected in the strategic approach implemented. According to the research results, organisations with a visionary strategic approach have a high degree of achieving the strategic goals. However, the highest threat to a satisfying implementation of the strategy are employees, being the basis for the creative potential. For that reason, the activities aimed at reducing the risk they generate seem to be the key area requiring the attention of managers. Therefore, several practical implications related to strategy implementation for companies with a visionary strategic approach could be formulated. The first would include the necessity to pay highest attention to risk factors concerning the intellectual capital and engagement of employees, whose knowledge and involvement significantly influence the probability of unsuccessful strategy implementation. Moreover, the overall perspective combining the operational activities with building the potential of creativeness seems to be the biggest managerial challenge. Further research could investigate other approaches and compare the results to identify the one that is significantly related to the intra-organizational risk included in the process of strategy implementation. The main limitation of the research presented concerns the data collection process that enabled to study the perception of respondents, not the actual features of strategy. Those latent variables represent the qualities that are not directly measured [Tabachnick, Fidell, 2001] and the constructs operating in the mental world of individuals [Borsboom, 2003, pp. 203-219]. 


\section{References}

1. Bonn, I., 2005. Improving strategic thinking: A multilevel approach. Leadership and Organization Development Journal, no. 26(5), p. 338.

2. Borsboom, D., Mellenbergh, G., van Heerden, J., 2003. The theoretical status of latent variables. Psychological Review, no. 110(2), pp. 203-219.

3. Bujor, A., Avasilcai, S., 2016. The Creative Entrepreneur: a Framework of Analysis. Procedia - Social and Behavioral Sciences, no. 221, p. 23.

4. Dean, T., Brown, R., Bamford, C., 1998. Differences in large and small firm responses to environmental context: strategic implications from a comparative analysis of business formations. Strategic Management Journal, no. 19, pp. 709-728.

5. Dewett, T., 2004. Creativity and strategic management: Individual and group considerations concerning decision alternatives in the top management teams. Journal of Managerial Psychology, vol. 19, iss. 2, p. 168.

6. Friedman, R., Forster, J., 2001. The effects of promotion and prevention cues on creativity. Journal of Personality and Social Psychology, no. 81(6), pp. 1001-1013.

7. Fundamental Concepts Of Excellence. EFQM, 2013, pp. 1-9

8. Lavoie, C., 2015. How to define a creative SME, Elsevier. 13th International Symposium in Management, no. 48, p. 214.

9. Mittchell, I., Walinga, J., 2017. The creative imperative: The role of creativity, creative problem solving and insight as key drivers for sustainability. Journal of Cleaner Production, no. 140, p. 1875.

10. Montag-Smit, T., Maertz, C., 2017. Searching outside the box in creative problem solving: The role of creative thinking skills and domain knowledge. Journal of Business Research, no. 81, pp. $1-10$.

11. Montuori, A., Purser, R., 1995. Deconstructing the lone genius myth. Journal of Humanistic Psychology, no. 35(3), pp. 69-112.

12. Rampersad, H., 2001. A visionary management model. The TQM Magazine, vol. 13, iss. 4, pp. 211-214.

13. Reeves, M., 2016. Leaders Beware: One Size Does Not Fit All When It Comes to Strategy. Leader to Leader, Winter, p. 24.

14. Reeves, M., Haanaes, K., Sinha, J., 2015. Your Strategy Needs a Strategy. How to Choose and Execute the Right Approach. Boston, Massachusetts: Harvard Business Review Press, pp. 215-217.

15. Roitzsch, K., Hacker, W., Pietrzyk, U., Debitz, U., 2012. How do German SMEs cope with the increasing need for flexibility? Advances in Decision Science, pp. 1-2.

16. Smircich, L., Stubbart, C., 1985. Strategic management in an enacted world. Academy of Management Review, vol. 10, no. 4, pp. 724-36.

17. Tabachnick, B., Fidell, L., 2001. Using Multivariate Analysis. Boston: Allyn and Bacon.

18. Thompson, L., 2003. Improving the creativity of organizational work groups. Academy of Management Executive, vol. 17, no. 1, p. 96. 
